\title{
Secular trends in incidence and recurrence rates of hip fracture: a nationwide population-based study
}

\author{
F.-P. Chen ${ }^{1,2,3}$ • Y.-C. Shyu ${ }^{4,5}$ - T.-S. Fu ${ }^{1,2,6}$ • C.-C. Sun ${ }^{1,7,8}$ • A.-S. Chao ${ }^{3}$ T.-L. Tsai ${ }^{6}$ • \\ T.-S. Huang $1,4,7,9$ (D)
}

Received: 8 August 2016 / Accepted: 25 October 2016 / Published online: 10 November 2016

(C) The Author(s) 2016. This article is published with open access at Springerlink.com

\begin{abstract}
Summary We assessed the incidence of hip fracture and second hip fractures in Taiwan from 2001 to 2012. Agestandardized incidence rates decreased after 2005. However, mortality rate after first hip fracture was substantial compared to second hip fracture rate in a competing risk model.

Introduction The aim of the study is to assess the incidence rates (IRs) of hip fractures, including changes in trends and medical costs, and second hip fractures in the Taiwanese population.

Methods The number of hip fractures and the associated medical costs were obtained from the annual report of the Ministry of Health and Welfare, Taiwan, for individuals $\geq 50$ years of age. The data of population at risk were retrieved from annual population reports from the Ministry of the Interior, Taiwan. The incidence of second hip fractures was evaluated from the National Health Insurance Research Database of Taiwan for insured individuals aged $\geq 50$ years from 2001 to 2011 with follow-up until 2013 using a competing risk model.
\end{abstract}

Electronic supplementary material The online version of this article (doi:10.1007/s00198-016-3820-3) contains supplementary material, which is available to authorized users.

\section{T.-S. Huang}

huangts1234@gmail.com

1 Keelung Osteoporosis Prevention and Treatment Center, Chang Gung Memorial Hospital, Keelung 204, Taiwan

2 Department of College of Medicine, Chang Gung University, Kwei-Shan, Taoyuan 259, Taiwan

3 Department of Obstetrics and Gynecology, Chang Gung Memorial Hospital, Keelung 204, Taiwan

4 Community Medicine Research Center, Chang Gung Memorial Hospital, Keelung 204, Taiwan
Results The IR for the entire population increased from 332.7 to 336.5 per 100,000 person-years during $2001-2005$ and decreased thereafter. This secular change was driven by a decrease in hip fractures for both men and women. The 10-year cumulative incidence rate of second hip fracture was $11.2 \%$ (95\% CI $11.0-11.5 \%$ ) in women and $7.9 \%$ (95\% CI 7.6$8.1 \%$ ) in men. Adjusted by consumer price index (CPI), the costs of hospitalization due to hip fracture increased from NTD 1.17 billion in 2001 to NTD 1.43 billion in 2012 . However, the CPI-adjusted costs of each admission decreased from NTD 74944 in 2001 to NTD 65791 in 2012.

Conclusions Since 2006, the IR of hip fractures has been declining in Taiwan. The 10-year cumulative IR of mortality is substantial for individuals who with first hip fracture.

Keywords Age-standardized incidence $\cdot$ Hip fracture $\cdot$ Medical economic costs $\cdot$ Second hip fracture $\cdot$ Trend

5 Institute of Molecular Biology, Academia Sinica, Nankang 115 Taipei, Taiwan

6 Department of Orthopaedic Surgery, Chang Gung Memorial Hospital, Keelung 204, Taiwan

7 Department of Chinese Medicine, College of Medicine, Chang Gung University, Kwei-Shan, Taoyuan 259, Taiwan

8 Department of Ophthalmology, Chang Gung Memorial Hospital, Keelung 204, Taiwan

9 Department of General Surgery, Chang Gung Memorial Hospital, 222 Mai-Chin Rd, Keelung 204, Taiwan 


\section{Introduction}

Hip fractures are considered to be of great concern because they may result in personal disability and mortality, thereby placing a burden on family and societal expenditures. It is estimated that approximately 1.66 million hip fractures occur each year worldwide [1,2]. According to recent world population surveys, the population of older adults (aged 60 years or over) in 2013 was 841 million, which is four times higher than the 202 million in 1950 [3]. The burdens associated with hip fracture could therefore be expected to become a great challenge worldwide.

Although several studies have demonstrated declining ageadjusted hip fracture rates for most Western countries over the past few decades [4-7], the incidence of hip fracture has increased two- to threefold in most Asian countries over the past 30 years [8]. Therefore, it is projected that by the year 2050, more than $50 \%$ of all osteoporotic hip fractures worldwide will occur in Asia [1,2]. Additionally, patients experiencing hip fractures have a twofold higher risk of subsequent hip fracture as compared to those without prior hip fractures [9]. Thus, the burden and significance of hip fracture may be greater than expected due to the impact of recurrent hip fractures.

In 2005, osteoporosis was declared as a government mandated national health priority in Taiwan. Since then, programs for osteoporosis prevention and public awareness have been promoted through the media and various groups in Taiwan. In addition, Asian-Pacific guidelines (2006) [10] and the Consensus and Guidelines on the Prevention of Adult Osteoporosis (The Taiwanese Osteoporosis Association, 2007) [11] were published. The efficacy of these measures was assessed by the National Nutrition and Health Survey in Taiwan (NAHSIT). The survey found an increase in calcium intake from food and an increase in the consumption of calcium and vitamin D supplements when comparing 2005-2008 with 1993-1996 [12, 13]. In order to quantify the burden of osteoporosis and to evaluate the potential impact of policy efforts, we conducted the present study to estimate the trend of the hip fracture incidence as well as economic burdens from 2001 to 2012. In addition, we used a whole population database, the National Health Insurance Research Database (NHIRD), to identify first hip fractures and to estimate 10-year second hip fracture probabilities in a competing risk model.

\section{Methods}

\section{Ethics}

This study was approved by the Ethical Medicine Committee of Chang Gung Memorial Hospital and supported by the Clinical Monitoring Research Program (CMRP) of Chang Gung Memorial Hospital at Keelung. The study protocol was also reviewed by the National Health Research Institute
(NHRI), which consented to the planned analysis of the National Health Insurance Research Database (NHIRD) data.

\section{Data sources}

This study included annual national reports from the Ministry of Health and Welfare, Taiwan (http://www.mohw.gov. tw/cht/DOS/Statistic_P.aspx?f_list_no $=312 \&$ fod_list no $=2425 \& d o c \_n o=13717$, accessed date 2015/07/06), annual population reports from the Ministry of the Interior, Taiwan, and NHIRD. The annual national reports from the Ministry of Health and Welfare, Taiwan, included aggregated count data (numerator in hip fracture incidence rates) of hip fractures (including first, recurrent, pathological hip fractures, and trauma) stratified according to age and sex groups. In addition, overall admission costs were provided. The data of population at risk were retrieved from annual population reports from the Ministry of the Interior, Taiwan (denominators in hip fracture incidence rates). The incidence of hip fractures and the associated medical costs were calculated from the annual report of the Ministry of Health and Welfare, Taiwan, and population reports from the Ministry of the Interior, Taiwan. NHIRD is an individuallevel claim database. The incidence of second hip fractures was calculated using the NHIRD, which contains records for approximately 23 million insured individuals. At the end of 2007, the NHIRD included information for more than $99 \%$ of the population enrolled in the National Health Insurance program, which has contracts with $97 \%$ of clinics and hospitals in Taiwan and covers all medical services received by each enrollee from 1996 to 2013, as well as the characteristics of the patients, hospitals, and physicians. For administrative use and research, the NHRI provided the research data, which are deidentified and encrypted before being released for medical research. We retrieved the whole population data of first hip fractures from the NHIRD.

\section{The incidence of hip fractures}

This study searched national databases for individuals aged 50 years and older who were diagnosed with hip fractures during the period from January 1, 2001 to December 31, 2012. The incidence of hip fractures and the associated medical costs were calculated from the annual report of the Ministry of Health and Welfare, Taiwan, and population reports from the Ministry of the Interior, Taiwan. The incidence rate (per 100,000 person-years) was defined as the number of occurrences of hip fractures divided by the age, sex-specific, mid-year population at risk. In addition, age-standardized incidence rates were calculated using the 2010 United Nations world population statistics as well $[14,15]$. 


\section{The incidence of second hip fractures}

Patients were identified from the database using the International Classification of Disease, 9th Revision, Clinical Modification (ICD-9-CM) diagnostic code for hip fractures (820.x) and surgical procedure code (64029B or 64170B) on their outpatient records or hospitalization discharge records. Pathological fractures were excluded. A total of 240,865 patients sustained their first hip fracture from January 1, 2001 to December 31, 2013; 14,503 traumatic cases that experienced traffic accidents (E810-E819, E881-E883, E8841) and 2463 patients with unknown sex, obscure records, or who were less than 50 years old were excluded. Additionally, 61,965 patients with a first hip fracture before January 1, 2001 and after December 31, 2011 were also excluded. Thus, a total of 161,934 patients $(62,823$ men and 99,111 women) with a first hip fracture between January 1, 2001 and December 31, 2011 were investigated and followed until December 31, 2013.

A patient's second hospitalization with a hip fracture diagnosis and surgical procedure codes was defined as a second hip fracture. The incidence rate of second hip fractures was estimated by treating death as a competing risk. The censoring was defined as no occurrence of second hip fracture or death until December 31, 2013.

\section{Statistical analysis}

We conducted a multivariate analysis using data from the hip fracture reports as mentioned above. To estimate the impact of policy interventions, we defined period 1 as the calendar years of 2001 to 2005 and period 2 as the calendar years of 2006 to 2012 . We first performed a Poisson regression and detected overdispersion [16]. Over-dispersion occurs when the Poisson distribution assumptions are likely violated. After exploring the possible sources of over-dispersion including outliers and interaction, we decided to use a negative binomial regression model (See Supplemental Table S1 for statistical details) to add in the additional variance term. Finally, we used the model to predict the hip fracture reduction between the two periods to identify the impact of policies to reduce hip fractures. Furthermore, we used a competing risk model to model the cumulative state-occupied probability of first hip fracture, second hip fracture, and death, with death as a competing event of second hip fracture [17, 18]. In addition, we also investigated the effect of age and sex on the event-specific incidence rate [19]. All reported confidence intervals (CIs) and tests were two-sided with a 5\% significance level. All analyses were performed using the $\mathrm{R}$ software version 3.3.1 (R Foundation for Statistical Computing, Vienna, Austria) with contributed packages "doBy," "epitools," "MASS," "mstate," and "compeir". All the R codes in the current study are available from the corresponding author.

\section{Results}

\section{Incidence of hip fractures}

According to the annual report from the Ministry of Health and Welfare, Taiwan, even though the overall number of hip fractures increased from 15,668 in 2001 to 21,775 in 2012, the incidence rate of hip fractures remained stable, from 332.7 to 336.5 per 100,000 person-years during $2001-2005$, and decreased thereafter from 314.5 to 295.9 per 100,000 personyears during 2006-2012 (Table 1). The age-standardized rate shows similar patterns.

The secular changes in hip fracture were similar for both women and men (Fig. 1a). The incidence rate of hip fracture increased with increasing age for both women and men. The

Table 1 Incidence rate of hip fracture according to year and sex

Number of hip fractures (incidence rate per 100,000 person-years)

\begin{tabular}{|c|c|c|c|c|c|c|}
\hline Calendar year & Women & $\begin{array}{l}\text { Age-standardized } \\
\text { IR for women }\end{array}$ & Men & $\begin{array}{l}\text { Age-standardized } \\
\text { IR for men }\end{array}$ & Total & Age-standardized IR ${ }^{\mathrm{a}}$ \\
\hline 2001 & $9137(393.5)$ & 432 & $6531(273.6)$ & 237.9 & $15,668(332.7)$ & 327.2 \\
\hline 2002 & $9800(402.3)$ & 441.5 & $6611(266.7)$ & 230.3 & $16,411(333.9)$ & 326.9 \\
\hline 2003 & $10,193(400.0)$ & 434.5 & $6943(270.1)$ & 233.5 & $17,136(334.8)$ & 326.1 \\
\hline 2004 & $10,777(404.4)$ & 439.2 & $7417(278.3)$ & 238.5 & $18,194(341.4)$ & 331 \\
\hline 2005 & $11,155(400.0)$ & 432.3 & $7533(272.5)$ & 233.8 & $18,688(336.5)$ & 324.9 \\
\hline 2006 & $10,843(371.2)$ & 398.9 & $7372(256.7)$ & 220.1 & $18,215(314.5)$ & 302.1 \\
\hline 2007 & $11,445(375.0)$ & 399.2 & $7428(249.8)$ & 211.7 & $18,873(313.2)$ & 298.9 \\
\hline 2008 & $12,226(384.4)$ & 406.9 & 7867 (255.9) & 217.2 & $20,093(321.2)$ & 305.6 \\
\hline 2009 & $12,415(374.4)$ & 394.2 & $8075(253.8)$ & 216 & $20,490(315.3)$ & 299.3 \\
\hline 2010 & $12,402(359.1)$ & 374.8 & $8191(248.8)$ & 211 & $20,593(305.3)$ & 288.2 \\
\hline 2011 & $13,058(363.8)$ & 375.8 & $8417(247.5)$ & 210.5 & $21,475(301.9)$ & 283.6 \\
\hline 2012 & $13,328(351.2)$ & 358.2 & $8447(237.0)$ & 201.6 & 21,775 (295.9) & 276.5 \\
\hline
\end{tabular}

${ }^{a}$ Age-standardized incidence rate was calculated using the 2010 United Nations world population statistics

IR incidence rate 
Fig. 1 Secular trend of incidence rate of hip fractures (per 100,000 person-years) in a the overall population, $\mathbf{b}$ women, and $\mathbf{c}$ men, stratified by age from 2001 to 2012

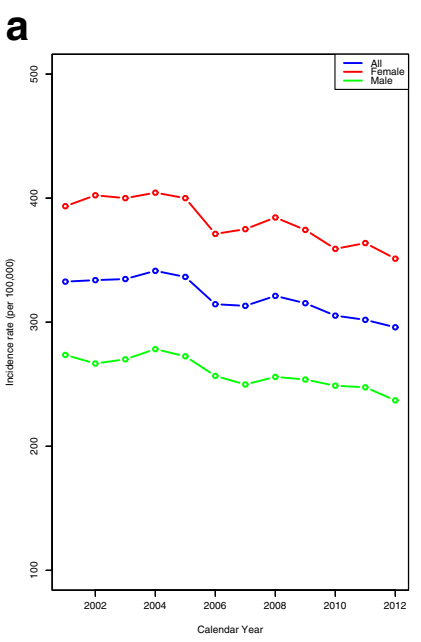

b

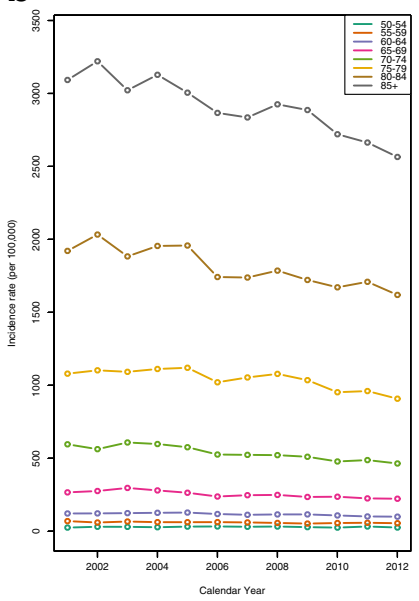

C

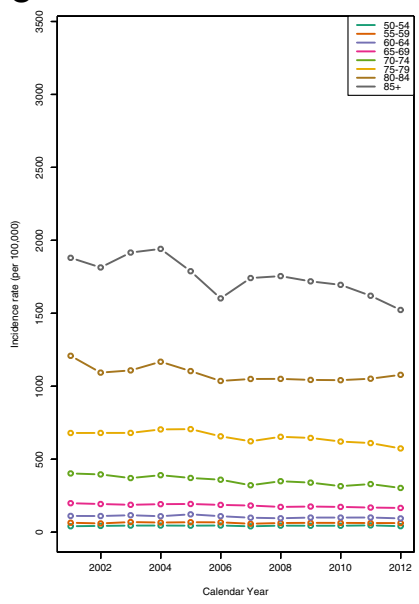

trend in the hip fracture rate for women aged 80 years or older was greater than that for men (Fig. 1b, c). When comparing the calendar periods 2001-2005 and 2006-2012, the expected number of hip fractures (adjusted for age, sex, and interactions in the negative binomial model) decreased across almost all age groups for both men and women (Supplemental Table S1), indicating that a period effect is present. In addition, the expected number reduction of hip fractures was greater for women at least 65 years old than it was for men (Fig. 2).

\section{Recurrence of hip fractures}

After extracting data from the NHIRD, there were 161,934 patients $(62,823$ men and 99,111 women) with a first hip fracture from 2001 to 2011, of whom 13,410 (4193 men and 9217 women) had experienced a second hip fracture by December 31, 2013. The median interval between the first and second hip fractures was 2.1 (interquartile range (IQR) 0.8-4.1) years (2.0 (IQR 0.73.9) years for men and 2.1 (IQR 0.9-4.2) years for women). Table 2 shows the state-occupied probability of first hip fracture, second hip fracture, and death under a competing risk model within 10 years. The 10year cumulative incidence rate of second hip fracture was $11.2 \%$ (95\% CI $11.0-11.5 \%$ ) in women and $7.9 \%$ (95\% CI $7.6-8.1 \%$ ) in men. Around half of the second hip fractures occurred within the first 3 years in women and in men. The 10-year cumulative incidence rate of death was substantial in women and men. Table 3 reveals that men have a lower event-specific incidence rate for second hip fracture (rate ratio (RR) 0.80 , 95\% CI 0.77-0.82) compared to women. However, men have a higher event-specific incidence rate for death (rate ratio (RR) 1.38 , 95\% CI 1.36-1.41) compared to women. The event-specific incidence rate for second hip fracture was highest in the age group between 80 and
Fig. 2 Expected reduction in number of hip fractures from period 1 to period 2 using a negative binomial regression model adjusted for age, sex, and interactions. Period 1: 2001-2005 calendar years. Period 2: 20062012 calendar years
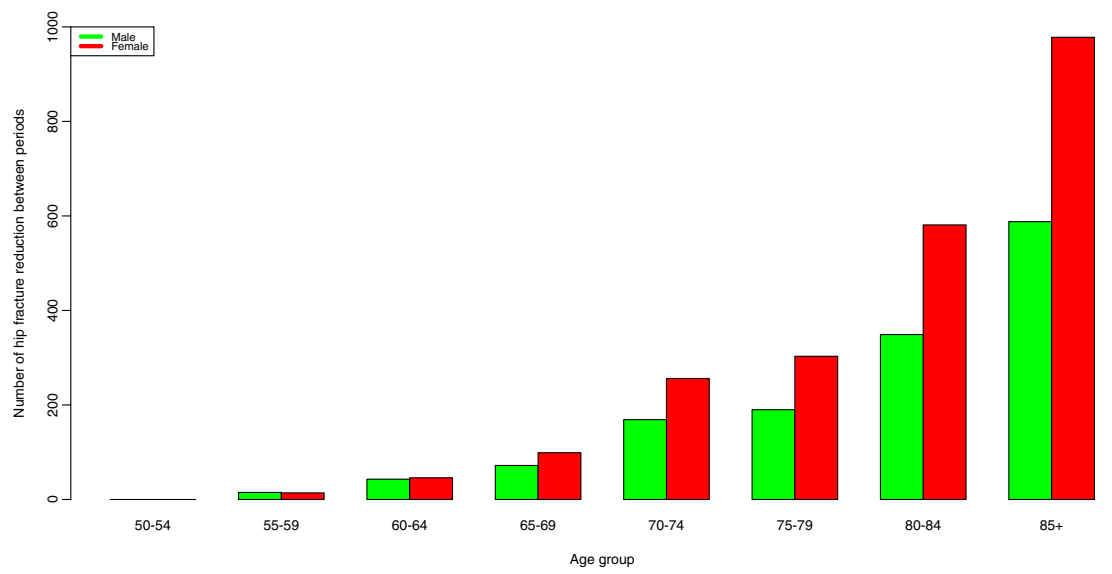


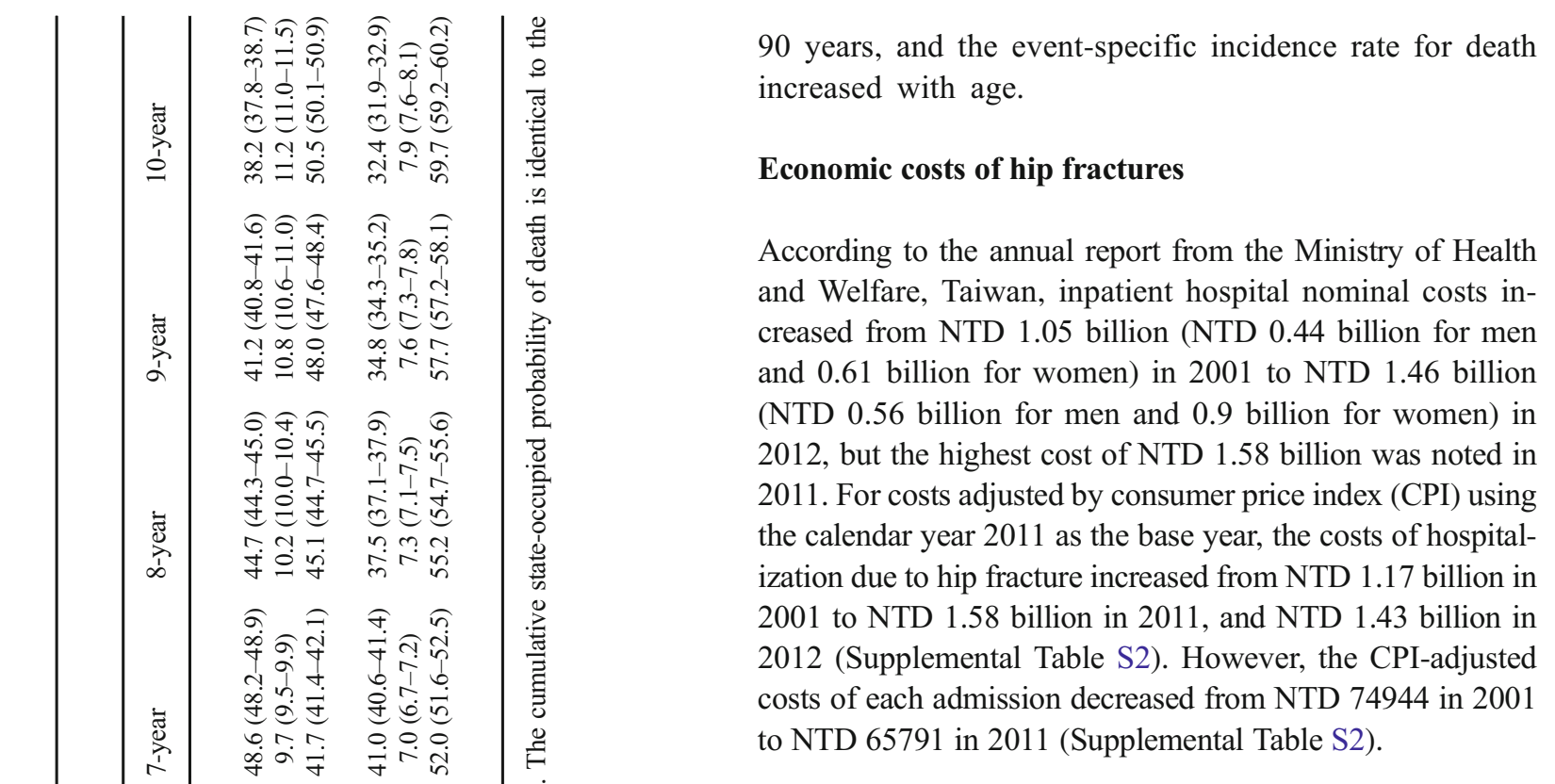

\section{Discussion}

The present study demonstrated the secular changes in hip fracture incidence rates in Taiwan. From 2001 to 2012, there was a significant reduction in the incidence of hip fracture. The secular trend for hip fracture reflects a difference between time periods (2001 to 2005 vs. 2006 to 2012) in all age groups for both men and women. Medical expenditures increased as the total annual number of hip fractures increased over time. However, the costs for each admission decreased. Among patients with their first hip fracture, the 10year mortality rate was substantial. To our knowledge, this is the most up-to-date report regarding the epidemiology of osteoporotic hip fractures and second fractures in an Asian country.

It has been well-established that the incidence of hip fracture increases with age [20], and the relative growth of the elderly population has been accompanied by a shift to an older average age at the time of hip fracture [21]. It has been documented that the earliest decreases in hip fracture rates were noted in the UK starting in the late 1970s and in North America starting in the mid-1980s, followed by Scandinavia, where rates started to decline in the early 1990s for Norway and Sweden, and the late 1990s for Denmark and Finland [7]. Although policy interventions and publishing of clinical practice guidelines have reduced the incidence rate of hip fracture, the number of hip fractures increased for both men and women due to an aging population. Compared with data for other countries, the decrease in incidence rate is not sufficient, indicating that our government and society should put more efforts on primary and secondary preventions [22]. Nevertheless, our estimates of hip fracture incidence included 
Table 3 Ratio between two event-specific incidence rates according to age and sex

\begin{tabular}{|c|c|c|c|c|}
\hline & \multicolumn{2}{|c|}{ Event 1: second hip fracture } & \multicolumn{2}{|l|}{ Event 2: death } \\
\hline & $\begin{array}{l}\text { Event-specific incidence } \\
\text { rate ratio }\end{array}$ & $95 \% \mathrm{CI}$ & $\begin{array}{l}\text { Event-specific incidence } \\
\text { rate ratio }\end{array}$ & $95 \% \mathrm{CI}$ \\
\hline \multicolumn{5}{|l|}{ Sex } \\
\hline Female & Reference & & Reference & \\
\hline Male & 0.80 & $0.77-0.82$ & 1.38 & $1.36-1.41$ \\
\hline \multicolumn{5}{|l|}{ Age, years } \\
\hline $50 \leqq$ Age $<60$ & Reference & & Reference & \\
\hline $60 \leqq$ Age $<70$ & 1.65 & $1.49-1.82$ & 1.79 & $1.70-1.88$ \\
\hline $70 \leqq$ Age $<80$ & 2.32 & $2.12-2.54$ & 2.67 & $2.55-2.79$ \\
\hline $80 \leqq$ Age $<90$ & 2.43 & $2.22-2.67$ & 3.64 & $3.48-3.81$ \\
\hline $90 \leqq$ Age & 1.99 & $1.78-2.24$ & 4.22 & $4.01-4.44$ \\
\hline
\end{tabular}

CI confidence interval first, recurrent, and traumatic hip fractures. The incidence rates are higher than previous reports [23].

Aside from being a decade or so behind these Western countries, the improving trend in Taiwan is quite similar to theirs. In Asia, most countries, such as China [24], Japan [25], South Korea [26], and Singapore [27], have shown a continuous increase in hip fracture rates in the current decade. However, findings regarding hip fracture rates similar to those in the present study have also been reported in Hong Kong [28]. The etiologies of the secular patterns in the aforementioned countries have not been completely clarified. Declared factors include urbanization, birth cohort effects, changes in bone mineral density and body mass index, osteoporosis medication use, and/or lifestyle interventions, such as smoking cessation, improvement in nutritional status, and fall prevention [7, 28]. In 2005, osteoporosis was declared as a government-mandated national health priority in Taiwan, which has facilitated the implementation of programs for osteoporosis prevention since then. The impact of these programs can be seen in the NAHSIT survey as well as our results.

Patients with prior hip fracture have about a twofold higher rate of subsequent hip fracture as compared to those without prior hip fractures [9]. The present study is the first to use the whole population data to analyze the occurrence of the second fracture in long-term follow-up. Melton et al. [29] conducted a long-term cohort study of hip fracture incidence and recurrence. Some of their results were similar to ours. First, the incidence rates of all hip fracture stratified by age and sex were similar with ours. Second, they showed that $23 \%$ of recurrent hip fractures occurred within 1 year following a first-ever hip fracture and $70 \%$ occurred within the first 5 years. Our analyses revealed that, following a first-ever hip fracture, $27 \%$ of recurrent hip fractures occurred within 1 year and $75 \%$ within the first 5 years in men, compared to $23 \%$ within 1 year and $72 \%$ within the first 5 years in women. Third, Melton et al. reported that the cumulative incidence of a second hip fracture after 10 years was $11 \%$ in women and $6 \%$ in men, with death treated as a competing risk. Nevertheless, our present study did not thoroughly investigate the period effect of secondary preventions. To our knowledge, there has been little Asian population-based research to determine the cumulative incidence of second hip fractures using a competing risk model as we did.

The incidence rate of second hip fractures has been reported with variable frequencies, ranging from 2.3 to $9.5 \%$ [30-40], which may be related to variations in the duration of follow-up, sample sizes, and statistical analysis. In accordance with the results reported by others [29, 39], increased age as an independent predictor of hip fracture recurrence was also identified in the present study. However, by age group, the event-specific incidence rate for second hip fracture was highest in patients aged 80-90 years. It was somewhat different from other reports regarding recurrent hip fracture [29, 30, 41], which increased linearly with age. In addition, the second hip fracture rate was higher in women than that in men in the present study, whereas other studies found no difference between men and women [29, 40, 41].

As the population aged, the number of hip fractures increased by $39 \%$ from 2001 to 2012 in Taiwan. Hospitalization costs also increased by $39 \%$ from 2001 to 2012. According to reports from the Directorate-General of Budget, Accounting and Statistics, Executive Yuan, Taiwan, the CPI increased by $13 \%$ from 2001 to 2012 . The average hospitalization cost per admission for hip fracture did not increase as the CPI increased, which was due to tight cost constraints by the Taiwanese National Health Insurance (NHI) [42]. However, it should not be ignored that it is difficult to estimate the expenditures by a family and society after a hip fracture. In addition, whether the strict limited health payment was related to the disease burden of hip fractures and recurrent hip fractures in Taiwan should be further investigated. Since 
Taiwan's compulsory national health care system covers $99 \%$ of Taiwan nationals, almost all patients with hip fractures would receive surgical treatment. The persistently high recurrent hip fracture and mortality rate demonstrates that, in addition to surgical management, better pharmacological [43] and rehabilitation [44] regimens comprising a comprehensive fracture prevention strategy, such as the Fracture Liaison Service model [45], may help to improve secondary preventions.

The main strengths of our study are that it is based on whole population data from the NHIRD for incidence rate of second hip fracture spanning 12 years and the incidence of hip fracture was assessed both from the annual report of the Ministry of Health and Welfare, and the Ministry of the Interior, Taiwan. Thus, it covers almost all hip fractures in Taiwan. In addition, our statistical analyses were rigorous. However, we also have limitations in the present study. First, it was unable to exclude completely the cases of re-operation due to short-term complications, since the operation code is similar. Hence, the number of second hip fractures in the present study may be slightly higher than that of the actual condition. Nevertheless, owing to the large sample size, the effect might be insignificant. Second, regarding declining rates, it is possible that the database in the latter period of the study is capturing a larger proportion of the aging population due to improved information technology, more complete data capture, and more insured patients included. If that is the case, then, the effects of policy interventions no longer exist. Finally, owing to a lack of the population at-risk data required for calculating incidence rate of first hip fracture, we could not conduct such an analysis in the present study.

Acknowledgements This study was supported by the Medical Research Center (Chang Gung Memorial Hospital, Keelung) and a research grant from the Clinical Monitoring Research Program (CMRPG2D0361, CMRPG2D0362, CMRPG2D0382 and CLRPG2C0024) of Chang Gung Memorial Hospital, Keelung.

\section{Compliance with ethical standards}

\section{Conflicts of interest None.}

Statement of human rights This article does not contain any studies with human participants or animals performed by any of the authors.

Informed consent For this type of study, formal consent is not required.

Open Access This article is distributed under the terms of the Creative Commons Attribution-NonCommercial 4.0 International License (http:// creativecommons.org/licenses/by-nc/4.0/), which permits any noncommercial use, distribution, and reproduction in any medium, provided you give appropriate credit to the original author(s) and the source, provide a link to the Creative Commons license, and indicate if changes were made.

\section{References}

1. Gullberg B, Johnell O, Kanis JA (1997) World-wide projections for hip fracture. Osteoporos Int 7(5):407-413

2. Cooper C, Campion G, Melton LJ 3rd (1992) Hip fractures in the elderly: a world-wide projection. Osteoporos Int 2:285-289

3. Division DoEaSAP (2013) World Population Ageing 2013 p. ST/ ESA/SER.A/348

4. Leslie WD, O'Donnell S, Jean S et al (2009) Trends in hip fracture rates in Canada. JAMA 302:883-889

5. Bergström U, Jonsson H, Gustafson Y, Pettersson U, Stenlund H, Svensson O (2009) The hip fracture incidence curve is shifting to the right: a forecast of the age-quake. Acta Orthop 80:520-524

6. Chevalley T, Guilley E, Herrmann FR, Hoffmeyer P, Rapin CH, Rizzoli R (2007) Incidence of hip fracture over a 10-year period (1991-2000): reversal of a secular trend. Bone 40:1284-1289

7. Ballane G, Cauley JA, Luckey MM, Fuleihan GE (2014) Secular trends in hip fractures worldwide: opposing trends East versus West. J Bone Miner Res 29:1745-1755

8. Mithal A, Dhingra V, Lau E, Stenmark J, Nauroy L (2009) The Asian Audit Epidemiology, costs and burden of osteoporosis in Asia 2009. International Osteoporosis Foundation 6. https://www. iofbonehealth.org/sites/default/files/PDFs/Audit\%20Asia/Asian_ regional audit 2009.pdf. Accessed 30 Oct 2016

9. Klotzbuecher CM, Ross PD, Landsman PB, Abbott TA, Berger M (2000) Patients with prior fractures have an increased risk of future fractures: a summary of the literature and statistical synthesis. J Bone Miner Res 15:721-739

10. Lau EM, Sambrook P, Seeman E, Leong KH, Leung PC, Delmas P (2006) Guidelines for diagnosing, prevention and treatment of osteoporosis in Asia. APLAR J Rheumatol 9:24-36

11. The Taiwanese Osteoporosis Association (2007) Clinical practice guidelines for the prevention and treatment of osteoporosis in Taiwan. The Taiwanese Osteoporosis Association, Taiwan, Taoyuan. http://www.hpa.gov. tw/English/file/ContentFile/201502140311199233/Taiwan\%20 Osteoporosis\%20Practice\%20Guidelines.pdf. Accessed 30 Oct 2016

12. Wu SJ, Pan WH, Yeh NH, Chang HY (2011) Trends in nutrient and dietary intake among adults and the elderly: from NAHSIT 19931996 to 2005-2008. Asia Pac J Clin Nutr 20:251-265

13. Chen SY, Lin JR, Chen TH, Guo SG, Kao MD, Pan WH (2011) Dietary supplements usage among elderly Taiwanese during 20052008. Asia Pac J Clin Nutr 20:327-336

14. Kanis JA, Odén A, McCloskey EV, Johansson H, Wahl DA, Cooper C (2012) A systematic review of hip fracture incidence and probability of fracture worldwide. Osteoporos Int 23:22392256

15. United Nations Development Programme (2015) Human Development Report 2015

16. Hilbe JM (2011) Negative binomial regression, second edition. Cambridge University Press, New York

17. Putter H, Fiocco M, Geskus RB (2007) Tutorial in biostatistics: competing risks and multi-state models. Stat Med 26:2389-2430

18. de Wreede LC, Fiocco M, Putter H (2011) mstate: an R package for the analysis of competing risks and multi-state models. J Stat Software 38:1-30

19. Grambauer N, Schumacher M, Dettenkofer M, Beyersmann J (2010) Incidence densities in a competing events analysis. Am J Epidemiol 172:1077-1084

20. Cummings SR, Melton LJ (2002) Epidemiology and outcomes of osteoporotic fractures. Lancet 359:1761-1767

21. Melton LJ 3rd, Therneau TM, Larson DR (1998) Long-term trends in hip fracture prevalence: the influence of hip fracture incidence and survival. Osteoporos Int 8:68-74 
22. Cauley JA, Chalhoub D, Kassem AM, Fuleihan GE (2014) Geographic and ethnic disparities in osteoporotic fractures. Nat Rev Endocrinol 10:338-351

23. Chie WC, Yang RS, Liu JP, Tsai KS (2004) High incidence rate of hip fracture in Taiwan: estimated from a nationwide health insurance database. Osteoporos Int 15:998-1002

24. Xia WB, He SL, Xu L et al (2012) Rapidly increasing rates of hip fracture in Beijing, China. J Bone Miner Res 27:125-129

25. Hagino H, Furukawa K, Fujiwara S et al (2009) Recent trends in the incidence and lifetime risk of hip fracture in Tottori, Japan. Osteoporos Int 20:543-548

26. Yoon HK, Park C, Jang S, Jang S, Lee YK, Ha YC (2011) Incidence and mortality following hip fracture in Korea. J Korean Med Sci 26: $1087-1092$

27. Lau EM (2009) The epidemiology of osteoporosis in Asia. IBMS Bone Key 6:190-193

28. Chau PH, Wong M, Lee A, Ling M, Woo J (2013) Trends in hip fracture incidence and mortality in Chinese population from Hong Kong 2001-09. Age Ageing 42:229-233

29. Melton LJ 3rd, Kearns AE, Atkinson EJ et al (2009) Secular trends in hip fracture incidence and recurrence. Osteoporos Int 20:687694

30. Nymark T, Lauritsen JM, Ovesen O, Röck ND, Jeune B (2006) Short time-frame from first to second hip fracture in the Funen County Hip Fracture Study. Osteoporos Int 17:1353-1357

31. Melton LJ 3rd, Ilstrup DM, Beckenbaugh RD, Riggs BL (1982) Hip fracture recurrence. A population-based study. Clin Orthop Relat Res 167:131-138

32. Chiu KY, Pun WK, Luk KD, Chow SP (1992) Sequential fractures of both hips in elderly patients - a prospective study. J Trauma 32: 584-587

33. Schroder HM, Petersen KK, Erlandsen M (1993) Occurrence and incidence of the second hip fracture. Clin Orthop Relat Res 289: $166-169$
34. Dretakis KE, Dretakis EK, Papakitsou EF, Psarakis S, Steriopoulos K (1998) Possible predisposing factors for the second hip fracture. Calcif Tissue Int 62:366-369

35. Weatherall M (1999) Contralateral fracture of the proximal femur. Bone Joint J 81:77-79

36. Wolinsky FD, Fitzgerald JF (1994) Subsequent hip fracture among older adults. Am J Public Health 84:1316-1318

37. Shabat S, Gepstein R, Mann G, Kish B, Fredman B, Nyska M (2003) The second hip fracture - an analysis of 84 elderly patients. J Orthop Trauma 17:613-617

38. Pearse EO, Redfern DJ, Sinha M, Edge AJ (2003) Outcome following a second hip fracture. Injury 34:518-521

39. Berry SD, Samelson EJ, Hannan MT et al (2007) Second hip fracture in older men and women: the Framingham Study. Arch Intern Med 167:1971-1976

40. Yamanashi A, Yamazaki K, Kanamori M et al (2005) Assessment of risk factors for second hip fractures in Japanese elderly. Osteoporos Int 16:1239-1246

41. Omsland TK, Emaus N, Tell GS et al (2013) Ten-year risk of second hip fracture. A NOREPOS study. Bone 52:493-497

42. Chang L, Hung JH (2008) The effects of the global budget system on cost containment and the quality of care: experience in Taiwan. Health Serv Manag Res 21:106-116

43. Morin S, Rahme E, Behlouli H, Tenenhouse A, Goltzman D, Pilote L (2007) Effectiveness of antiresorptive agents in the prevention of recurrent hip fractures. Osteoporos Int 18:1625-1632

44. Stenvall M, Olofsson B, Lundström M et al (2007) A multidisciplinary, multifactorial intervention program reduces postoperative falls and injuries after femoral neck fracture. Osteoporos Int 18: 167-175

45. Eisman JA, Bogoch ER, Dell R et al (2012) Making the first fracture the last fracture: ASBMR task force report on secondary fracture prevention. J Bone Miner Res 27:2039-2046 